\title{
Mass-Weighted Isentropic Zonal Mean Equatorward Flow in the Northern Hemispheric Winter
}

\author{
Toshiki Iwasaki ${ }^{1}$ and Yasushi Mochizuki ${ }^{2}$ \\ ${ }^{1}$ Graduate School of Science, Tohoku University, Sendai, Japan \\ ${ }^{2}$ Okinawa Meteorological Observatory, Naha, Japan
}

\begin{abstract}
In the diagnosis of mass-weighted isentropic zonal mean (MIM), the mean- meridional circulation has a strong extratropical direct (ETD) cell in the northern- hemispheric winter, which turns from downward to equatorward around $45^{\circ} \mathrm{N}$ and isentropic zonal mean pressure of $850 \mathrm{hPa}$. The January mean equatorward flow in the extratopical lower troposphere is almost in balance with Eliassen-Palm (E-P) flux divergence for both climatology and interannual variability. This means that the zonal mean equatorward flow in the extratropical lower troposphere is the wave-induced circulation as well as the poleward flow in the stratosphere is.

The interannual variation of January mean mass stream functions at $\left(45^{\circ} \mathrm{N}, 850 \mathrm{hPa}\right)$ positively (negatively) correlates with the zonal mean temperature in the lower troposphere north (south) of about $45^{\circ} \mathrm{N}$, respectively. This is consistent with a simple thermodynamic consideration that the strong ETD circulation adiabatically warms up the lower troposphere due to the descending flow in the higher latitudes but cools it down due to the heat advection by the equatorward flow in the middle latitudes $\left(\sim 35^{\circ} \mathrm{N}\right)$.
\end{abstract}

\section{Introduction}

The mass-weighted isentropic zonal mean (MIM) enables us to describe the Lagrangian mean meridional circulation (Gallimore et al. 1981; Andrews 1983; Townsend et al. 1985; Tung 1986; Iwasaki 1989, 1990 and 1992; Juckes et al. 1994; Juckes 2001). In MIM, very differently from the conventional zonal mean, the mass stream function has a distinct extratropical tropospheric direct (ETD) circulation in the winter hemispheres, in addition to the Hadley circulation (Iwasaki 1989 and 1992; Juckes et al. 1994; Juckes 2001). In particular, the strong zonal mean equatorward flow appears in the lower troposphere.

What is the driving force of isentropic zonal mean equatorward flow in the lower troposphere? One of the possible mechanisms is wave-mean flow interactions, which were formulated in Transformed Eulerian-Mean method (TEM, Andrews and McIntyre 1976) and in isentropic coordinates (Andrews 1983; Tung 1986; Iwasaki 1989). In the stratospheric Brewer-Dobson circulation, the driving force of the poleward flow has been recognized to be the geostrophic adjustment to wave-induced zonal momentum convergence (e.g., Dunkerton 1978). Many studies confirmed that the E-P flux convergence is almost in balance with the Coriolis force of mean poleward flow in the extratropical stratosphere. The meridional gradient of wave forcing induces vertical motions below through the meridional mass convergence, that is, "Downward control principle" (Haynes et al. 1991). The wave driving of mean meridional flow through the geostrophic adjustment is called as "the extratropical pumping" (Holton et al. 1995). In the upper branch of ETD circulation, the poleward flow is almost in balance with the E-P flux convergence (Tanaka et al. 2004). Thus, we study whether or not the extratropical pumping is a major forcing to induce the mean equatorward mass flux in

Corresponding author: Toshiki Iwasaki, Graduate School of Science, Tohoku University, Aramaki, Aoba-ku, Sendai, 980-8578, Japan. E-mail: iwasaki@wind.gp.tohoku.ac.jp. (C2012, the Meteorological Society of Japan. the lower troposphere as well as the poleward flux in the upper troposphere. TEM is, however, difficult to see wave-mean flow interactions in the lower troposphere because of ill-conditioning at the lower boundary. Therefore, few works have been done to analyze the zonal mean equatorward flow in the lower troposphere.

MIM is extension of TEM to a proper expression of wavemean flow interactions in the vicinity of the lower boundary. In baroclinic instability waves, intersections of isentropes with the lower boundary are essential for the mean equatorward flow, E-P flux divergence and their angular momentum balance in the lower troposphere (Iwasaki 1990). Jukes et al. (1994), in his isentropic analysis, indicated a quasigeostrophic balance between the E-P flux divergence and the Coriolis torque exerted by mean meridional flow in the lower troposphere. In this work, the relationship is analyzed of monthly mean equatorward mass flux with E-P flux divergence in the lower troposphere, intended to develop a diagnostic tool for climate analyses from the viewpoint of angular momentum balance.

In MIM, the thermodynamic equation simply expresses the zonal mean-meridional heat transport without any eddy correlation terms. In the extratropics, the lower-tropospheric mean equatorward flow, which substantially transports the polar cold air mass, can be regarded as the zonal-mean polar cold air outbreak. Particular attention is paid to impacts of lower-tropospheric equatorward flow on the zonal mean temperature in the lower troposphere.

\section{Mean-meridional circulation in MIM}

In our scheme, any dependent variable takes isentropic zonal mean along isentropic lines with normalized mass weight,

$$
\overline{A^{*}} \equiv \overline{A \frac{\partial p}{\partial p_{\dagger}}},
$$

where overbars and asterisks indicate isentropic zonal means and normalized longitudinal mass-weights, respectively (Iwasaki 1989). For brevity, isentropic zonal mean pressures $p_{*}(\phi, \theta)=\bar{p}$ are adopted as vertical coordinates, instead of isentropic coordinates. Constant $p_{*}$ lines are parallel to isentropic lines nearby in the zonal direction, except that they become the ground lines when the isentropes intersect the ground. The potential temperature $\theta\left(\phi, p_{\dagger}\right)$ can be presented inversely as a function of latitude and isentropic zonal mean pressure. Note that the longitudinal contribution to zonal means is variable due to the mass weight as seen in Eq. (1). In particular, this becomes zero for $\theta<\theta_{s}$.

The mass stream function $\chi\left(\phi, p_{\dot{\dagger}}\right)$ is basically defined as the total northward mass flux above an isentropic zonal mean pressure $p_{\dagger}$ at a given latitude $\phi$,

$$
\begin{aligned}
\chi\left(\phi, p_{\dagger}\right) & \equiv \frac{2 \pi a \cos \phi}{g} \int_{0}^{p_{\dagger}} \overline{v^{*}} d p_{\dagger} \\
& =-\frac{a \cos \phi}{g} \int_{0}^{2 \pi} \int_{\theta\left(\phi, p_{\dagger}\right)}^{\infty} v \frac{\partial p}{\partial \theta} d \theta d \lambda,
\end{aligned}
$$

where $\lambda$ is longitude. Note that order of integration is changeable between $\theta$ and $\lambda$, since the mass weight is included. The mass stream function $\chi\left(\phi, p_{\dagger}\right)$ is almost equal to total equatorward mass flux below $\theta\left(\phi, p_{\dot{\dagger}}\right)$, although its small difference arises from the 
temporal change in meridional distribution of zonal mean surface pressure,

$$
\begin{aligned}
\chi\left(\phi, p_{\dot{\dagger}}\right) & \approx-\frac{2 \pi a \cos \phi}{g} \int_{p_{\dagger}}^{p_{s z}} \overline{v^{*}} d p_{\dagger} \\
& =\frac{a \cos \phi}{g} \int_{0}^{2 \pi} \int_{\theta_{s}}^{\theta\left(\phi, p_{\dagger}\right)} v \frac{\partial p}{\partial \theta} d \theta d \lambda .
\end{aligned}
$$

This indicates the thermally stratified equatorward mass flux in the lower troposphere.

The mass stream function and E-P flux are evaluated from the JRA-25 reanalysis (Onogi et al. 2007). Figure 1 shows the meridional cross sections of the January mean mass stream function and the E-P flux averaged over 1980-2010. The mass stream function has a distinct extratropical tropospheric direct (ETD) circulation in the northern hemisphere. The ETD circulation has a sharp and strong equatorward flow confined below an isentropic zonal mean pressure of about $850 \mathrm{hPa}$ in northern mid-latitudes. The turning point of the ETD circulation from the downward to equatorward is located around $45^{\circ} \mathrm{N}$ latitude and the isentropic zonal mean pressure of $850 \mathrm{hPa}$. The value of the mass stream function at this point represents the magnitude of the ETD circulation and, hereafter, is regarded as an index for the stratified equatorward flow in the lower troposphere.

\section{Driving forces of zonal mean equatorward flow in the lower troposphere}

As mentioned in Section 1, one of the possible mechanisms to drive the mean equatorward flow in the lower troposphere is the extratropical pumping associated with wave-mean flow interactions. The lower panel of Fig. 1 shows that there is a sharp E-P flux divergence zone in the extratropical lower troposphere. MIM
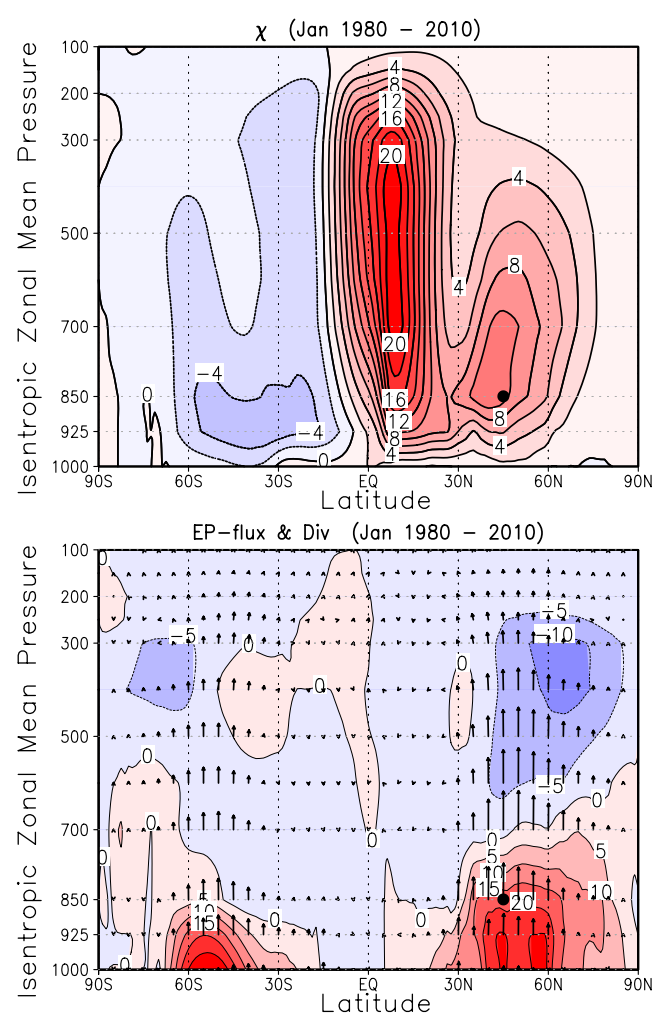

Fig. 1. Meridional cross sections of (Upper panel) mass stream function with contour intervals of $2 \times 10^{10} \mathrm{~kg} \mathrm{~s}^{-1}$ for $1000-100 \mathrm{hPa}$ and (Lower panel) E-P flux (unit; $\mathrm{kg} \mathrm{s}^{-2}$ ) and its divergence (unit; $\mathrm{m} \mathrm{s}^{-1}$ day $^{-1}$ ), where E-P flux is scaled down so as to keep the scaling ratio of vertical to horizontal components equivalent to that of vertical to horizontal axes. Points of $\left(45^{\circ} \mathrm{N}, 850 \mathrm{hPa}\right)$ are indicated by closed circles. diagnosis expresses the zonal mean equatorward flow and E-P flux divergence in the extratropical lower troposphere. Here, the extratropical pumping relationship is examined of the zonal mean equatorward flow in the lower troposphere. In the extratropics, dominant terms in the zonal mean zonal momentum equation (see Appendix) are the Coriolis force of meridional flow and the E-P flux divergence. Their balance can be written as

$$
f \overline{v^{*}} \approx-\frac{\nabla \cdot \mathbf{F}}{a \rho_{0} \cos \phi} .
$$

Meridional divergence of the E-P flux is negligibly small compared with the vertical one in the lower troposphere. Both of mass stream function and E-P flux are also very small at the ground. Thus, the vertical integration of extratropical pumping relationship Eq. (4) becomes

$$
\chi\left(45^{\circ} \mathrm{N}, 850 \mathrm{hPa}\right) \approx \frac{2 \pi}{f} F_{Z_{\dagger}}\left(45^{\circ} \mathrm{N}, 850 \mathrm{hPa}\right) .
$$

The mass stream function is expected to be proportional to the vertical component of the E-P flux at the same point.

Figure 2 shows the interannual variability of January means of the mass stream function and vertical E-P flux at the point $\left(45^{\circ} \mathrm{N}, 850 \mathrm{hPa}\right)$. In the zonal mean zonal momentum Eq. (A1), major contributions are made from the Coriolis force and E-P flux divergence of about $30 \mathrm{~m} \mathrm{~s}^{-1}$ (day) $)^{-1}$ below $850 \mathrm{hPa}$. As a result, the acceleration due to E-P flux divergence is in balance with deceleration due to Coriolis force of mean-meridional flow. Thus, the extratropical pumping is considered to be the major driving force of the equatorward mean flow in the mid-latitude lower troposphere. The mass stream functions are about 80 percents of the vertical E-P flux multiplied by $2 \pi / f$ as shown in Fig. 2 . The difference is attributed to the remaining terms of A1, i.e., advection and friction terms. The ratio of stream function to E-P flux depends weakly on the latitude, because of the variations of advection and friction terms.

The interannual variation of monthly mean mass stream function at the point $\left(45^{\circ} \mathrm{N}, 850 \mathrm{hPa}\right)$ is highly correlated with that of vertical component of E-P flux. Thus, E-P flux is a good indicator of the strength of the stratified zonal mean equatorward flow. In the northern hemispheric winter, the vertical E-P flux in the extratropics was shown to mainly come from transient long waves and stationary ultra-long waves (Tanaka et al. 2004). Thus, the interannual variability of mass weighted isentropic zonal mean equatorward flow in the lower troposphere may be closely related to long and ultra-long wave activity. In reality, Eady's baroclinic instability waves hold the extratropical pumping relation near the lower boundary, where both the mean-meridional flow and E-P flux divengence result from intersections of isentropes with the

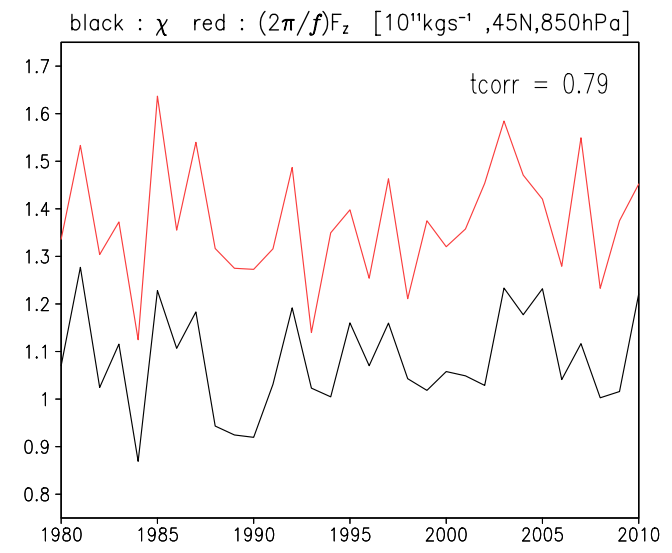

Fig. 2. Interannual variations of mass stream function (black) and vertical component of E-P flux multiplied by the factor of $(2 \pi / f)$ at $45^{\circ} \mathrm{N}$ and isentropic zonal mean pressure of $850 \mathrm{hPa}(\mathrm{red})$. 
ground along the zonal direction (Iwasaki 1990).

The equatorward transport of cold air mass is deeply associated with the energy conversions. MIM represents a cascade-type energy conversion diagram, if the wave energy is defined as a sum of eddy available potential energy and eddy kinetic energy (Iwasaki 2001; Uno and Iwasaki 2006). The ETD circulations convert zonal mean available potential energy to zonal mean kinetic energy, and wave-mean flow interactions do zonal mean kinetic energy to wave energy. The two energy conversion rates become equivalent to each other under the condition of quasi-geostrophic balance. Iwasaki and Kodama (2011) showed that the Eady's growth rate is consistent with the energetic in MIM. Thus, instability of long and ultra-long waves is essential for the stratified equatorward flow in the lower troposphere.

\section{Impacts of mean equatorward flow on the ther- modynamic state in the lower troposphere}

In MIM, the zonal mean thermodynamic equation, which does not have any eddy transport terms as seen in Eq. (A3), makes it easy to consider conceptual models for the zonal mean thermodynamic states. In the northern hemispheric winter, the ETD circulation is expected to adiabatically warm up the lower-tropospheric temperature due to the descending flow in high latitudes, but cool it down due to the horizontal heat advection by the equatorward flow below about $p_{\dagger}=850 \mathrm{hPa}$ in mid-latitudes. In the lower troposphere, the warming must switch to the cooling around the turning latitude of $45^{\circ} \mathrm{N}$.

Figure 3 illustrates meridional cross sections of correlation and regression coefficients of potential temperature with the mass stream function $\chi\left(45^{\circ} \mathrm{N}, 850 \mathrm{hPa}\right)$ for 31 Januaries during1980-2010. In this case, the level of significance becomes 95 percents when the correlation coefficient is about 0.35 . Having a look at the correlation map, statistically significant are the warming at around $60^{\circ} \mathrm{N}$ and cooling at around $35^{\circ} \mathrm{N}$. Figure 4 plots meridional cross sections of regression coefficients of zonal mean vertical and meridional flows with $\chi\left(45^{\circ} \mathrm{N}, 850 \mathrm{hPa}\right)$. The anomaly of $\chi\left(45^{\circ} \mathrm{N}, 850 \mathrm{hPa}\right)$ corresponds to anomalies of ascending (descending) flows at around $35^{\circ} \mathrm{N}\left(60^{\circ} \mathrm{N}\right)$ above $850 \mathrm{hPa}$ and equatorward flow between $30^{\circ} \mathrm{N}$ and $60^{\circ} \mathrm{N}$ below about $850 \mathrm{hPa}$. The ascending (descending) causes adiabatic cooling (warming) above $850 \mathrm{hPa}$ around $35^{\circ} \mathrm{N}\left(60^{\circ} \mathrm{N}\right)$, respectively. Below $850 \mathrm{hPa}$, the mean equatorward flow causes the advective cooling. The advective cooling partly offsets downward adiabatic warming north of $45^{\circ} \mathrm{N}$ and reduces temperature south of $45^{\circ} \mathrm{N}$. Note that

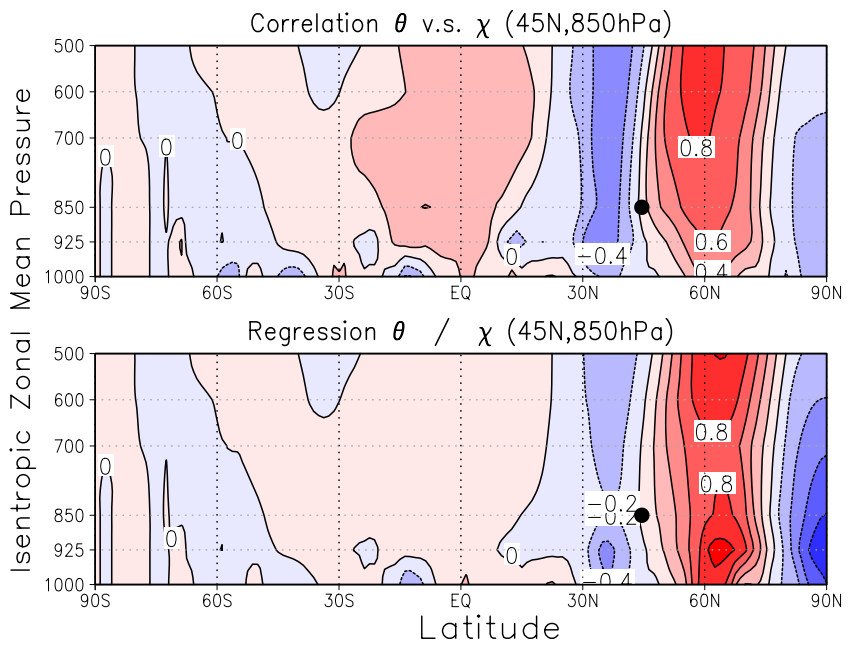

Fig. 3. Meridional cross sections of correlation and regression of potential temperature with the mass stream function $\chi\left(45^{\circ} \mathrm{N}, 850 \mathrm{hPa}\right)$, where the regression is presented with a unit of $10^{-10} \mathrm{~K} \mathrm{~kg}^{-1} \mathrm{~s}$. Points of $\left(45^{\circ} \mathrm{N}\right.$, $850 \mathrm{hPa}$ ) are indicated by closed circles.

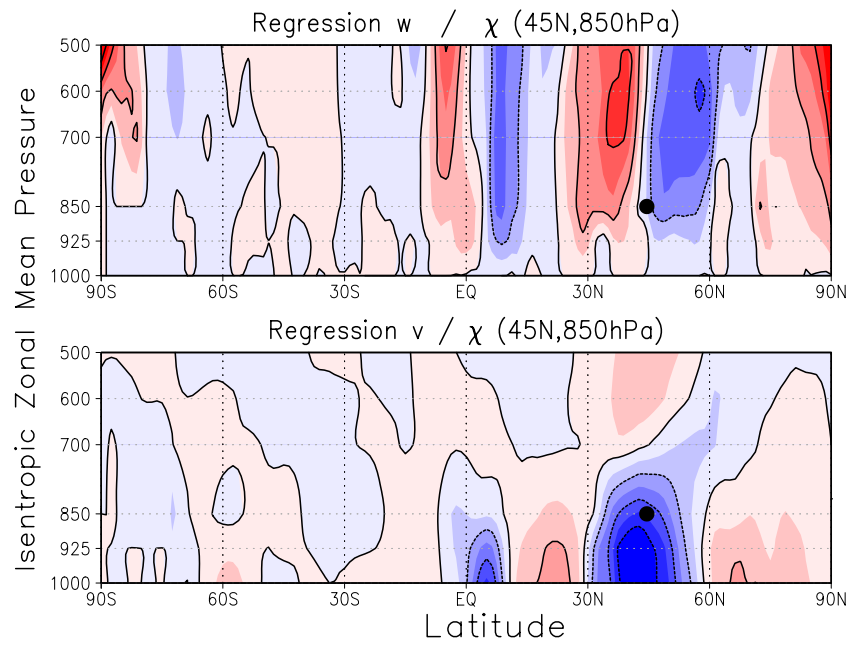

Fig. 4. Meridional cross sections of regressions of (Upper panel) zonal mean vertical wind and (Lower panel) meridional wind with the mass stream function $\chi\left(45^{\circ} \mathrm{N}, 850 \mathrm{hPa}\right)$. Warm (cool) colors indicate positive (negative) values with arbitrary contour intervals. Points of $\left(45^{\circ} \mathrm{N}\right.$ $850 \mathrm{hPa}$ ) are indicated by circles.

the increase of potential temperature at the isentropic zonal mean pressure does not exactly indicate the increase of isobaric zonal mean temperature, but indicates the increase of cold air mass below $\theta\left(\phi, p_{\dagger}=850 \mathrm{hPa}\right)$.

\section{Conclusions and discussions}

Mass weighted-isentropic zonal mean (MIM) is capable of diagnosing a distinct extratropical direct (ETD) circulation in the northern hemispheric winter, which turns from downward to equatorward around $45^{\circ} \mathrm{N}$ and isentropic zonal mean pressure of 850 $\mathrm{hPa}$. In the lower troposphere, the zonal mean equatorward flow almost satisfies the so called "extratropical pumping relationship" for the climatology and interannual variability, where its Coriolis force is in balance with E-P flux divergence. Interannual variation of E-P flux is contributed more to by stationary ultra-long waves than transient long waves (Kodama et al. 2010). The equatorward flow interannually varies under greater influence of stationary ultra-long wave activity.

The interannual variation of mass stream functions at $\left(45^{\circ} \mathrm{N}\right.$, $850 \mathrm{hPa}$ ) positively (negatively) correlates with the low-level zonal mean temperature north (south) of about $45^{\circ} \mathrm{N}$, respectively. This is consistent with a simple thermodynamic conceptual model that the distinct ETD circulation warms up the lower troposphere due to the descending flow in the high latitudes, but cools it down due to the equatorward flow in mid-latitudes $\left(\sim 35^{\circ} \mathrm{N}\right)$.

Statements on the thermodynamic state deduced from the MIM analysis, that is, warming in high latitudes and cooling in middle latitudes, must be applicable limitedly to the isentropic zonal mean state, but not applicable to regional climate variability. As mentioned above, stationary waves play an important role in the formation of the equatorward flow. In addition, the low-level stratified flow must be significantly influenced by the topography. Further study is needed to explore axially asymmetric structures of stratified equatorward flow in the lower troposphere.

\section{Acknowledgements}

Authors would like to express sincere thanks to two anonymous reviewers for providing valuable comments on our manuscript. This study is supported in part by the Japanese Ministry of Education, Culture, Sports, Science and Technology through a Grant-in-Aid for Scientific Research in Innovative Areas \#2205. 


\section{Appendix}

In MIM, zonal mean zonal momentum equation based on isentropic zonal mean pressure $p_{\uparrow}$ is written in a spherical form (Iwasaki 1992; Tanaka et al. 2004) as

$$
\frac{\partial \overline{u^{*}}}{\partial t}=-\frac{\overline{v^{*}}}{a \cos \phi} \frac{\partial \overline{u^{*}} \cos \phi}{\partial \phi}-\overline{w_{\dagger}^{*}} \frac{\partial \overline{u^{*}}}{\partial z_{\dagger}}+f \overline{v^{*}}+\frac{\nabla \cdot \mathbf{F}}{a \rho_{0} \cos \phi}+\overline{X^{*}},
$$

where E-P flux is given by

$$
\begin{aligned}
\mathbf{F} & =\left(F_{\phi}, F_{z_{+}}\right) \\
& =\rho_{0} a \cos \phi\left[-\overline{\left(u^{\prime} v^{\prime}\right)^{*}}, \overline{\left(u^{\prime} w_{\dagger}^{\prime}\right)^{*}}+\frac{1}{\rho_{0} g a \cos \phi} \overline{p\left(\frac{\partial \Phi}{\partial \lambda}\right)_{p_{\dagger}}}\right] .
\end{aligned}
$$

The first term of vertical E-P flux is attributed to eddy diabatic mixing of momentum and meridional gradient of isentropic surfaces, and the second term is to the form drag over isentropic surfaces. Zonal mean thermodynamic equation is written as

$$
\frac{\partial \theta}{\partial t}=-\frac{\overline{v^{*}}}{a} \frac{\partial \theta}{\partial \phi}-\overline{w_{\dagger}^{*}} \frac{\partial \theta}{\partial z_{\dagger}}+\overline{\left(\frac{Q}{\Pi}\right)^{*}}
$$

where $\Pi$ and $Q$ are the Exner function and external heating.

\section{List of symbols}

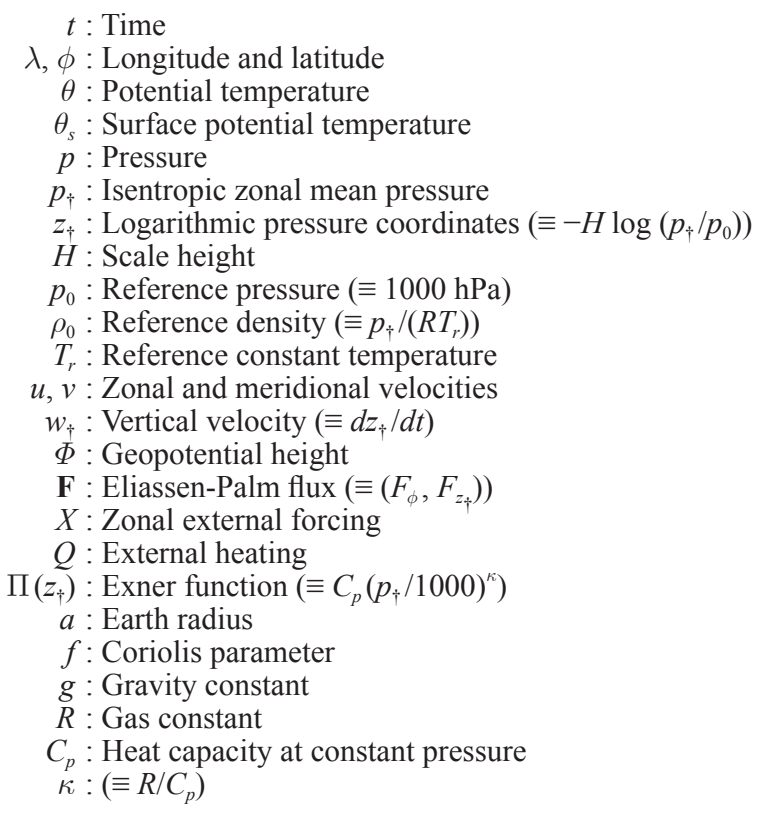

\section{References}

Andrews, D. G., 1983: A finite-amplitude Eliassen-Palm theorem in isentropic coordinates. J. Atmos. Sci., 40, 1877-1883.

Andrews, D. G., and M. E. McIntyre, 1976: Planetary waves in horizontal and vertical shear: The generalized Eliassen-Palm relation and mean-zonal acceleration. J. Atmos. Sci., 33, 2031-2048.

Dunkerton, T., 1978: On the mean meridional mass motions of the stratosphere and mesosphere. J. Atmos. Sci., 35, 2325-2333.

Gallimore, R. G., and D. R. Johnson, 1981: The forcing of the meridional circulation of the isentropic zonally averaged circumpolar vortex. J. Atmos. Sci., 38, 583-599.

Haynes, P. H., C. J. Marks, M. E. McIntyre, T. G. Shepherd, and K. P. Shine, 1991: On the "downward control" of extratropical diabatic circulations by eddy-induced mean zonal forces. $J$. Atmos. Sci., 48, 651-678.

Holton, J. R., P. H. Haynes, M. E. McIntyre, A. R. Douglass, B. Rood, and L. Pfister, 1995: Stratosphere-troposphere exchange. Rev. of Geophys., 33, 403-439.

Iwasaki, T., 1989: A diagnostic formulation for wave-mean flow interactions and Lagrangian- mean circulation with a hybrid vertical coordinate of pressure and isentrope. J. Meteor. Soc. Japan, 67, 293-312.

Iwasaki, T., 1990: Lagrangian-mean circulation and wave-mean flow interactions of Eady's baroclinic instability waves. $J$. Meteor. Soc. Japan, 68, 347-356.

Iwasaki, T., 1992: General circulation diagnosis in the pressureisentrope hybrid vertical coordinate. J. Meteor. Soc. Japan, 70, 673-687.

Iwasaki, T., 2001: Atmospheric energy cycle viewed from wave, mean-flow interaction and Lagrangian mean circulation. $J$. Atmos. Sci., 58, 3036-3052.

Iwasaki, T., and C. Kodama, 2011: How does the vertical profile of baroclinicity affect the wave instability? J. Atmos. Sci., 68, 863-877, doi:10.1175/2010JAS3609.1.

Juckes, M. N., 2001: A generalization of the transformed Eulerian-mean meridional circulation. Quart. J. Roy. Meteor. Soc., 127, 147-160.

Juckes, M. N., I. N. James, and M. Blackburn, 1994: The influence of Antarctica on the momentum budget of the southern extratropics. Quart. J. Roy. Meteor. Soc., 120, 1017-1044.

Kodama, C., Y. Mochizuki, S. Hasegawa, T. Iwasaki, and M. Watanabe, 2010: Negative correlation between the interannual variabilities of the stationary and transient wave energy in the northern hemisphere. SOLA, 6, 37-40, doi:10.2151/ sola.2010-010.

Onogi, K., J. Tsutsui, H. Koide, M. Sakamoto, S. Kobayashi, H. Hatsushika, T. Matsumoto, N. Yamazaki, H. Kamahori, K. Takahashi, S. Kadokura, K. Wada, K. Kato, R. Oyama, T. Ose, N. Mannoji, and R. Taira, 2007: The JRA-25 reanalysis. J. Meteor. Soc. Japan, 85, 369-432.

Tanaka, D., T. Iwasaki, S. Uno, M. Ujiie, and K. Miyazaki, 2004: Eliassen-Palm flux diagnosis based on isentropic representation. J. Atmos. Sci., 61, 2370-2383.

Townsend, R. D., and D. R. Johnson, 1985: A diagnostic study of the isentropic zonally averaged mass circulation during the First GARP Global Experiment. J. Atmos. Sci., 42, 15651579.

Tung, K. K., 1986: Nongeostrophic theory of zonally averaged circulation. Part I: Formulation. J. Atmos. Sci., 43, 2600-2618.

Uno, S., and T. Iwasaki, 2006: A cascade type global energy conversion diagram based on wave-mean-flow interactions. $J$. Atmos. Sci., 63, 3277-3295.

Manuscript received 4 July 2012, accepted 25 August 2012

SOLA: http://www.jstage.jst.go.jp/browse/sola 